Tercedor Sánchez, M. \& Casado Valenzuela, A. (2018). Visual metaphors in representing medical knowledge. Linguistica Antverpiensia, New Series: Themes in Translation Studies, 17, 174-195.

\title{
Visual metaphors in representing medical knowledge
}

\author{
Maribel Tercedor Sánchez
}

Universidad de Granada, Spain

itercedo@ugr.es

\author{
Alicia Casado Valenzuela \\ Universidad de Almería, Spain \\ aliciacv@ual.es
}

Understanding the role of mental images and embodiment in metaphorical thought is fundamental to the study of metaphor in science in general, and in medicine in particular. And analysing typologies of metaphorical images and their function is a key issue in assessing their success in disseminating knowledge, since knowledge construction depends on the interaction between verbal and visual information (Ketola, 2016). In this article, we describe the premises and methodological steps followed in analysing and describing visual metaphorical information in medical texts for lay audiences. We follow a data-driven approach in which images were extracted from the VariMed database, a multimodal terminographical tool for translation, linguistic research and knowledge dissemination. An experiment was carried out to explore how successfully metaphorical images used as illustrations for specific medical concepts were identified and understood. We conclude that metaphorical images were preferred over non-metaphorical illustrations for medical concepts, which may point to lay audiences' familiarity with metaphorical multimodal references.

\section{Introduction}

Multimodal scenarios have become commonplace in the information society, superseding a long-lasting tradition of supremacy of the verbal over the visual, particularly in Western societies. In Translation Studies, Baker (2014, p. 15) emphasizes the focus on non-verbal material and how there is a blurring of the boundaries between translation and other types of text production. Images substantially enhance the meaning expressed by words (Nikolajeva, 2014, p. 713), hence the recognition of meaning as multimodal. In this context, metaphor plays a key role in conceptualizing and disseminating knowledge, reinforcing different ways of making sense of particular aspects of our lives (Semino, Demjen, \& Demnen, 2018). Multimodal metaphor is a fundamental focus of study in cognition, as it is acknowledged that metaphor is now a recognized cognitive phenomenon that helps us to understand one thing in terms of another. Furthermore, metaphorical conceptualizations often transcend language, raising interest in them in areas such as multimodality studies.

In medicine, complex abstract phenomena are understood in terms of concrete tangible phenomena and embodied metaphors such as emotions are forces offer cultural nuances that demand a close study. Conceptual Metaphor Theory (CMT) (Lakoff \& Johnson, 1980, p. 153) points to the role of embodiment, such as gestures, in metaphorical conceptualizations. CMT accounts for the interaction between embodiment, cognition, language and culture (Gibbs, 2006). Multimodal metaphor involves metaphors whose target and source are each represented exclusively or predominantly in different modes (Forceville, 2006, p. 384). In medicine, verbo-pictorial metaphors are frequent, reflecting as they do at least two distinct scenarios, which are quite different in scope: (1) a 
metaphorical designation based on resemblance or (2) an extended conceptual metaphor grounded in an image schema.

The study of images in translation and terminology is crucial, given their role in promoting the understanding of specialized concepts and in boosting creativity (Tercedor, Alarcón Navío, Prieto-Velasco, López-Rodríguez, 2009). In multimodal scenarios, terminology management and translation must take into consideration the interrelation between semiotic modes. However, as Smith and Kosslyn (2007, p. 70) stress, in order to succeed in contributing to knowledge acquisition, there must be a correspondence between the perceptual input from images and the stored representations of knowledge in memory. Such representations include metaphor.

Metaphorical images in medicine are the result of concrete resemblance, embodiment and recurrent image schemas. Despite the embodied nature of many metaphorical motivations, the understanding of metaphor is not always easy, as metaphoric conceptualizations might be culture-dependent or require specialized knowledge for their meaning to be grasped. Pictures, portraits and realistic paintings are the prototypes of iconic signs. However, symbolic and iconic images may be interpreted very differently even by people sharing similar cultural values. Finally, representing abstract concepts may pose a challenge, which can be solved through the use of metaphor (Barsalou, 1999; Gibbs, 1994; Johnson, 1987; Lakoff \& Johnson, 1980).

In this article, we focus on the study of metaphorical images from the perspective of their use in describing specialized concepts. We first overview the different types of metaphorical images and their role in transmitting medical knowledge. The source of data is VariMed, a multimodal terminological database (http://varimed.ugr.es). In an online terminographical tool such as VariMed, images are a functional tool and as such they can be used for pedagogical purposes, in which role they can contribute to understanding abstract concepts, to recalling new concepts, to stimulating imagination and to expressing emotions as well as to activating previous concepts (e.g.. García Morales, 2012; Sánchez Benítez, 2009). VariMed is anchored in Frame-based Terminology (Faber, 2012), a terminological theory that points to the use of corpora to extract knowledge and to the importance of multimodal resources in describing terminology. Our focus is on delving into multimodal terminology management for the purposes of translation and scientific dissemination.

This article is divided into eight sections. Section 2 deals with conceptual and resemblance metaphors; the role of metaphorical images in relation with the referent is described in section 3; section 4 focuses on cultural motivations of metaphorical reference; section 5 is concerned with metaphor framing and saliency; in section 6 we describe the codification of images in terminological description, focusing on the VariMed database; in section 7 we describe an experiment on the understanding of metaphorical images, and, finally, in section 8 we add some final remarks.

\section{Conceptual and resemblance metaphors}

Metaphors are important in communication and cognition because they express, reflect, and reinforce different ways of making sense of particular aspects of our lives (Semino et al., 2016, p. 1). Metaphor is a cross-domain phenomenon, which can be classified into different types. Cognitive Linguistics makes the distinction between conceptual metaphor and image metaphor (Lakoff \& Turner, 1989), even though both kinds of metaphor involve mapping concepts from one domain to another. The difference lies in the fact that image metaphors are conceptually simple in that only one concept of the source domain maps onto the target domain, whereas conceptual metaphors are more complex in their domain-to-domain mapping of different features not necessarily related to resemblance exclusively but also to behaviour (Tercedor Sánchez, López Rodríguez, Márquez Linares, \& Faber, 2012, p. 35). As such, image metaphors are based on a sense-perceived 
resemblance between two entities, and are the result of image-to-image mappings, which results in one expression. For example, observe the two metaphorical medical images in Figure 1:

\begin{tabular}{|l|l|l|}
\hline Concept & Referent and metaphorical motivation & Image \\
\hline $\begin{array}{l}\text { (1) STRAWBERRY } \\
\text { GALLBLADDER }\end{array}$ & $\begin{array}{l}\text { Gallbladder has the appearance of a } \\
\text { strawberry as a result of the presence } \\
\text { of cholesterol [metaphor based on } \\
\text { resemblance]. }\end{array}$ \\
\hline (2) CLOUDED SENSORIUM & $\begin{array}{l}\text { Mental obfuscation represented by } \\
\text { clouds or fog [conceptual } \\
\text { metaphor]. }\end{array}$
\end{tabular}

Figure 1: Resemblance (1) and conceptual (2) metaphors in medical images

The illustrations above show important differences in scope and productivity. "Strawberry gallbladder" is an illustration of a terminological metaphor in medicine emerging because of the resemblance between a particular medical concept and a physical referent, as it also happens in "butterfly rash" or "crow's feet". Whereas the image of "strawberry gallbladder" is a metaphorical reference based on morphological similarity, the image for "clouded sensorium" is based on an extensive mapping of blurred, clouded spaces onto psychological conditions. In the case of the example of "clouded sensorium" above, even though the concept is abstract, its visualization through a metaphorical image that resembles the concept helps to clarify it. The conceptual image of a cloud with blurred boundaries is mapped onto the unclear structure of a psychological condition. An image schema is in force, leading to further lexicalizations and great productivity: "brain fog", "clouding of consciousness", etc. Conceptual images are often based on extended image schemas, such as more is up (Lakoff \& Johnson, 1980), as they occur in representations in graphics. Image schemas are indeed recurrent patterns of perception and bodily movement (Johnson, 2005, p. 29) that derive from our sensory-perceptual experience with our body (Johnson, 1987, p. xix). In fact, visually representing concepts that are not visual is a common device in medical knowledge representations. As Tversky (2001) maintains: "A major purpose of graphic displays is to visually represent concepts and relations that are not inherently visual" (p. 111). In psychological and emotional concepts, metaphor allows us to grasp a more subjective concept:

Thoughts have a structure that can be rendered in words, but feelings, like sensations, do not. All we can do, therefore, is to describe in words the external situations or thoughts associated in our memory or in our imagination with the feeling in question and to trust that our reader or listener will grasp what particular feelings are meant (Wierzbicka, 1972, p. 59).

It is therefore no coincidence that many metaphorical expressions used in Psychology are also pervasive in non-specialized language: 


\begin{tabular}{cl}
\hline \hline Ese campo de caricias abonado de espesa niebla & mental, exacerbados los sentidos del tacto, el gusto, el olfato, la vista \\
\hline efinitiva voz propia, desea despejar cualquier niebla & mental en pos de hablar con su pasado, una vez que lo estuviera acc \\
\hline Jnambúlico, entre espasmos de lucidez y una niebla & mental que se levantaba de tanto en tanto para que pudiera entregarı \\
\hline que intuyó, desde el fondo de una especie de niebla & mental, que, por el bien de muchas personas, no debia permanecer i \\
\hline \hline
\end{tabular}

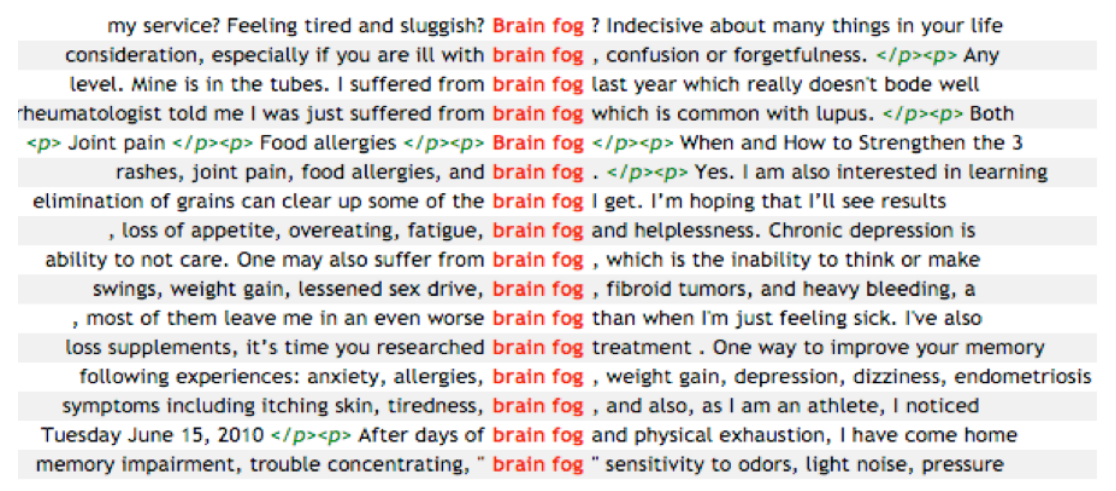

Figure 2: Concordances of niebla mental in the esTenTen 2011 corpus and "brain fog" in the EnTenTen 2012 corpus

Visually representing metaphorical concepts such as those contained in the concordances above is thus a common device that reinforces and helps with understanding the metaphorical motivation of a concept, connecting with its different interlinguistic designations. Furthermore, it has been shown that the areas of the brain responsible for visual information about concepts become particularly active when subjects are asked to pay attention to the visual aspects of images and to make visual simulations (Barsalou, 2008a).

\section{Role of metaphorical images in relation to a referent}

In specialized communication, images are used to communicate ideas, express emotions and visually represent the invisible. This feature gives images the potential to be a vehicle for metaphor. Metaphorical images may reflect either mental images or physical realities (Forrester, 2000, p. 15; Prieto \& Faber, 2012, p. 226). Photographs may be either realistic or abstract in nature, but their representativeness may differ depending on the relationship with the referent, the concept or the text they accompany. In this sense, it is interesting to note that images can be realistic but show no relationship to the referent; alternatively, abstract images may relate directly to a referent, especially if they illustrate mental images of the concept. In the examples in Figure 3, the photograph used to illustrate the concept allergy has low representativeness in relation to the concept, since it contains only a trace of the conceptual features of allergy. It is a picture containing trees, which makes it necessary to accompany the image with a textual description pointing to the connection between vegetation and allergy. On the other hand, the image used to illustrate amnesia, despite being abstract, depicts the conceptual definition, namely, the inability to remember things, via an illustration that refers to the mental image of deleting something. 


\begin{tabular}{|l|l|}
\hline & \\
\hline $\begin{array}{l}\text { Realistic image used to illustrate } \\
\text { the concept allergy } \\
\begin{array}{l}\text { Source: } \\
\text { http://varimed.ugr.es/imagenes/ } \\
835 / 291 . j p g\end{array}\end{array}$ & $\begin{array}{l}\text { Abstract image used to } \\
\text { illustrate the concept } \\
\text { amnesia. Source: } \\
\text { http://varimed.ugr.es/imag } \\
\text { enes/173/728.jpg }\end{array}$ \\
\hline
\end{tabular}

Figure 3: Realistic vs. abstract image. Source: varimed.ugr.es

In previous work, Tercedor Sánchez (2011) explored the "ways of seeing" concept by Croft and Cruse (2004, p. 137), namely, the multidimensionality of concepts revealing the different ways of looking at the same thing. This notion has been developed and implemented in VariMed, in the classification of terminological variants (cf. Tercedor Sánchez, 2017). It is based on the need to consider the cognitive motivation of variation, with conceptual designations focusing on particular foci of conceptual information. These in turn reveal semantic relationships created by the choice of a term variant, based on the argument that terms are a reflection of our interaction with the world surrounding us, a verbalization of our embodied and situated conceptualization (Barsalou, 2008b; Gibbs, 2006). From a situated perspective of medical realities, the perceptual characteristics of an entity, a disease or its symptoms provide an important basis for metaphorical mappings. They are therefore are a good source for image selection, since they are likely to express the salient features of a concept. Consequently, physical symptoms that can be visualized may be referred to primarily by perceptual references such as texture and visual attributes. However, images based on resemblance may be ambiguous or represent different referents, depending on how the linking relationships in the accompanying text are established (Barsalou, 1999, p. 584). For example, an image of a naked ankle with a red area on it could be used for inflammation, pain, arthritis or other joint conditions.

\section{Cultural motivation for metaphorical images}

Metaphorical images based on physical resemblance are often shared between languages, as is the case with English and Spanish. Resemblance takes place mainly between the lexicalizations for signs and symptoms and the objects they depict, as happens in the following EN-ES pairs extracted from our corpus: "port wine stain" = manchas en vino de Oporto and "drumstick fingers" = dedos en palillo de tambor; lexicalizations can also involve plants, animals or other elements from nature: "strawberry gallbladder" = vesícula en fresa, "butterfly rash" = erupción en forma de mariposa, "moon face" = cara de luna llena and "nutmeg liver" = hígado en nuez moscada. 
However, in other cases, the metaphor has a specific cultural motivation and therefore reveals a difference in lexicalization, as in "goose bumps" = piel de gallina and "crow's feet" = patas de gallo.

Moreover, it is often the case that the metaphorical term is an alternative designation for a more cryptic term: "acropaquia" (drumstick fingers) $=$ dedos en palillo de tambor.

All of these are metaphorical terms based on resemblance and therefore can be illustrated using a metaphorical image in line with their resemblance-based designation. For example, "broken-heart syndrome" is a metaphorical term designating stress-induced cardiomvopathv, as expressed in the definition: "Broken-heart syndrome', also called 'stress-induced cardiomyopathy' or 'takotsubo cardiomyopathy', can strike even if you're healthy. (Takotsubo, by the way, are octopus traps that resemble the pot-like shape of the stricken heart.)"

The above lexicalization is based on the image schema of the heart is a container, which is based in turn on the image schemas in-out and up-down (López-Rodríguez \& Tercedor-Sánchez, 2017). In contrast, "Takotsubo" is a cultural-metaphorical term as observed in the explanation in the quotation above.

In addition, the image below (Figure 4) shows a metaphorical motivation based on the heart is a container image schema, and illustrating the resemblance with a familiar object.

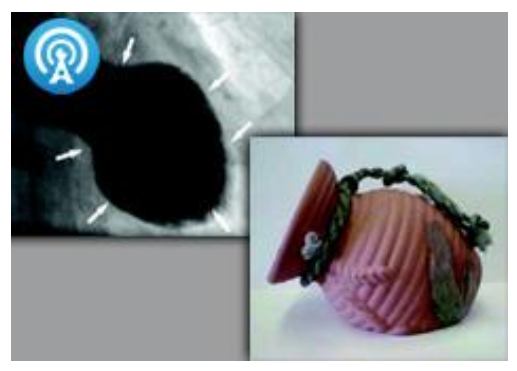

Figure 4: Illustration of "Takotsubo (stress) Cardiomyopathy". Source: C Templin, JR Ghadri \& J Diekmann. New England Journal of Medicine 2015;373:929-938.

Other relevant terminological metaphors point to human activities which typically lead to a particular condition, sign or symptom. These include "athlete's foot", "tennis elbow", "bishop's hand" and "housemaid's knee". Finally, embodied terminological metaphors based on processes such as "tickling" or "burning" may also find visual correspondences, such as the illustration of a stomach on fire to illustrate "heartburn".

In other cases, where the conceptual metaphor has a more complex basis, they need to be interpreted because they may not necessarily be based on resemblance but rather on behaviour. As a result, their understanding and acceptance depend on the comprehender's background knowledge. In order to create the analogy, therefore, the following cognitive steps are followed: (1) the relevant terms are accessed from long-term memory; (2) the source is mapped to the target to identify correspondences; (3) analogical inferences are made about the target, creating new knowledge, and (4) learning occurs when new links are created in memory (Holyoak \& Hummel, 2001). Such is the case with "mirror syndrome" and many psychological conditions, as well as the many eponymic terms based on children's literature and the psychological features of the protagonists of the stories: "Alice in Wonderland syndrome", "Rapunzel syndrome", "Peter Pan syndrome", etc. Their mapping becomes difficult if no access to the metaphorical correspondences can be made. 
Metaphors are both an element of the structure of bodily experience and emerge from experience (Johnson, 1987; Lakoff \& Johnson, 1980). Gibbs (1999) stresses the role of our physical experience in understanding and states that meaning is motivated by "people's recurring bodily experience in the real world" (p. 39). The role of our experience in perceiving disease constitutes the experiential, phenomenological basis of embodied metaphors. Let us observe the image in Figure 5 to see how viewers' previous experience of art can activate relevant features of emotional states related to depression.

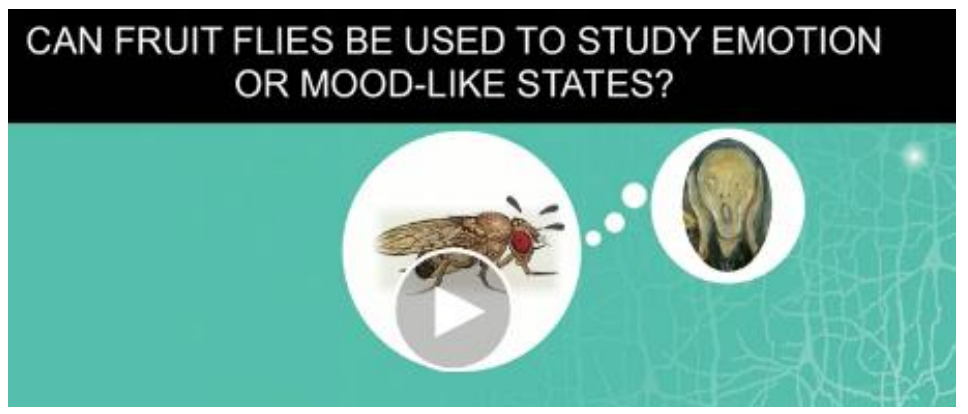

Figure 5: Photogram of David Anderson's TED talk entitled "Our brain is more than a bag of chemicals".Source:https://www.ted.com/talks/david_anderson_your_brain_is_more_than_a_bag_of_ chemicals\#t-306081

The embodied nature of source domains is a fundamental issue in concrete, clear-cut signs and symptoms. However, recognition of the source domain may be constrained by culture (Kövecses, 2005; Lakoff \& Turner, 1989, p. 66). Forceville (2006) argues that when we map the source onto the target, cultural motivation is more relevant than embodiment. As the author states (Forceville, 2006), it is connotations rather than denotations that are mapped in metaphors. In this regard, observe the following image used to illustrate the concept somatic symptom disorder, defined as a form of mental disorder that causes different bodily symptoms such as pain. The use of a voodoo doll to illustrate the concept has a cultural motivation, potentially making it a difficult depiction of the concept for those lacking this specific world knowledge.

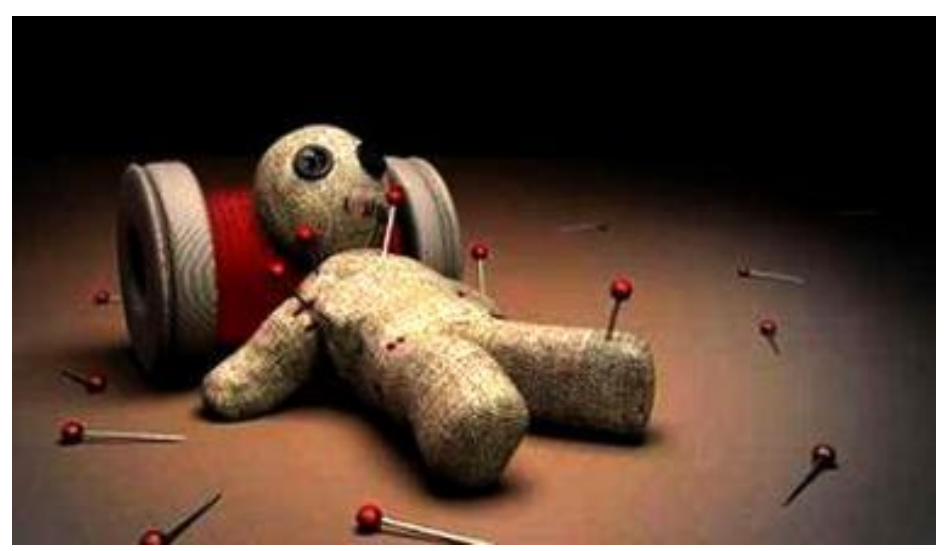

Figure 6: Image used to illustrate the concept somatic symptom disorder Source: http://psicologiandouny.blogspot.com.es/2015/09/trastornos-somatomorfos-una-vida-con.html 
Lakoff (1987) discusses multimodal metaphors such as anger is heat. In medicine, a case in point is the use of colour to illustrate medical symptoms. Darker shades of red are associated with negative emotions (Apresjan, 1995, pp. 372-373). Red is universal as a pointer to pain and inflammation. Red is pain is a common image schema in medicine (cf. "myalgia", "localized pain", etc.). However, in non-Western contexts such as Japanese culture, red is used in combination with blue to illustrate inflammation (Kitao $\&$ Kitao, 1986). In our corpus, there is a clear interrelationship between pain is heat, pain is red and disease is red.

The image accompanying "transient ischemic attack" = accidente isquémico transitorio shows a red spot to place the focus on pain and a clock as an image of transition, constituting a hybrid visual metaphor or a blending space (Fauconnier \& Turner, 2002). Both ideas could be considered universal; however, in certain cultures, such as Japanese, the associated ideas for red are shown in blue. Moreover, purple is a colour used to show inflammation as it has a physical resemblance to inflamed areas, but in Japanese culture it is hardly used. It could be the case that since purple is a colour whose only connotation in Japanese is royalty (Kitao \& Kitao, 1986, p. 73), its use in medical contexts is avoided. Other instances are "to feel blue", "to be in a blue mood", phraseological expressions showing a metaphorical relationship between their components based on blending (Fauconnier \& Turner, 2002). Awareness of these cultural issues is key to communicating successfully in intercultural translation scenarios.

\section{Metaphor framing and saliency}

For an image to be relevant in illustrating a medical concept, it should contain salient conceptual features. The concept of saliency derives from the notion of conceptual specificity described in Prototype Theory (Rosch, 1978). According to this theory, basiclevel categories are more salient but not necessarily more frequent. Therefore, salient features may not correspond in frequency to the linguistic occurrences in a corpus. In this context, Radden (1992) refers to prototypes as being perceptually more salient. According to Forceville (2016), saliency is related to the degree of realism in the metaphorical motivation: if salience is a consequence of realistic motivation, salient images should also be more realistic. This notion is crucial since selecting the salient (or prototypical) features of a concept in an illustration could contribute to the acquisition of the concept's main features and, as a result, to the acquisition of knowledge. Cognition is guided by selecting what is relevant to the comprehender. We bring information closer in the way that we make assumptions to find it relevant; in other words, we pay attention to whatever responds to our expectations in an information scenario.

Some authors (e.g., Celikkale, Eerdem, \& Eerdem, 2015) have carried out research into image memorability, establishing links between image saliency and memorability and concluding that features such as the presence of close-up human faces favour memorability (Celikkale et al., 2015, p. 40). If this holds for the case of medical images, the presence of embodied features and human features in many metaphorical images and terms would explain their high saliency and memorability. Since the perception and conceptual representation of information involve a processing cost, the most salient and easily representable information at a given time is likely to be the most relevant information at that point (Sperber, Cara, \& Girotto, 1995, p. 49). As Prieto and Faber (2012) put it: "comprehension involves extracting defining features from real-world entities to create concepts ... a snapshot process" (p. 226).

The Praggleiaz Group (2007) specifies some interesting characteristics for the meaning of a lexical unit to be considered basic-level. For our purposes this is relevant because our images are conceived to illustrate a concept, which in turn is lexicalized by one or more lexical units. According to Praggleiaz Group $(2007$, p. 3) basic meanings tend to be "more concrete, what they evoke is easier to imagine, see, hear, feel, smell and 
taste; related to bodily action; more precise (as opposed to vague); historically older". From this, it follows that the more concrete might be more basic-level and it may also correlate to being closer to an embodied conceptualization.

\section{Codifying images in terminological description: the VariMed database}

Images have become a point of interest of terminology since they are acknowledged to be a crucial element in knowledge acquisition. In multimedia scenarios, images contribute to easing the extrinsic cognitive load; that is, the cognitive load imposed by the format and manner in which information is presented and by the working memory requirements of the instructional activities (Brünken, Plass, \& Leutner, 2003, p. 54). In terminological description, images should be pertinent, since they are chosen with the objective of capturing and conveying relevant features of concepts. In fact, pictorial representations may be able to convey more information than propositional ones and they may do so in ways that lend themselves to different methods of interpretation (Hookway, 2007, p. 60). Leppink and Van der Heuvel (2015, p. 123) stress the importance of providing visual information in medical education materials: "information that could best be presented visually should not be transmitted verbally."

VariMed is a medical terminological database intended as an aid to translating, knowledge dissemination and writing, based on the premises of Frame-based Terminology (Faber, 2012). This is a cognitively oriented theory of terminology that stresses the importance of multimodal information in describing terminology for cognitive and communicative purposes. VariMed (http://varimed.ugr.es) currently contains 1266 concepts, with information on the different designations or terminological variants for each concept amounting to more than 5000 terminological designations (which gives a mean ratio of 4.2 terminological variants or designations for every concept). In addition, concepts are defined and relationships are established between concepts. As images may enrich understanding of medical concepts both qualitatively and quantitatively, special attention has been paid to the inclusion of images for every concept in the database. In this regard, concepts are illustrated by means of images $(n=1132)$ that were extracted from a multimodal corpus compiled from online medical texts. The research focus for the construction and enrichment of VariMed is on facilitating the acquisition of linguistic and visual knowledge about diseases, medical signs and symptoms. Starting from the consideration that "images represent meaning more directly than alphabetic written languages" (Tversky, 2001, p. 80), the classification of images prior to their selection for knowledge acquisition is crucial.

\subsection{Classification of images in VariMed}

Three main criteria are applied when classifying images for terminological purposes. First, images are extracted from medical texts of different genres composing our corpus and selected to enter the terminological database for the purpose either of illustrating prototypical and salient features of the concepts they represent (e.g., a person washing her hands to illustrate obsessive compulsive disorder) or of illustrating the concept in a decorative manner, that is, not pointing to a particular feature of the concept. This choice is most likely influenced by the inherent nature of particular concepts that are difficult to illustrate visually (e.g., a person coughing to illustrate $d r y$ cough). This criterion is what we have termed "representativeness" and have assigned three levels to it: low, medium and high.

Secondly, there is information about the degree of specialization of each image (low-medium-high). This differentiation is necessary because some images could be comprehensible only to experts, whereas others could be useful only for illustrating basic 
facts - for instance, those used in children's texts. A filtered and customized search in the database allows images with a specific degree of specialization and representativeness to be retrieved.

Thirdly, images are classified as either abstract or realistic, depending on their resemblance to the concept being focused on. In this sense, medical conditions showing visual features tend to be represented by realistic images, whereas conditions, signs and symptoms with no visual attributes are usually represented in an abstract manner.

\begin{tabular}{|c|c|c|c|c|c|c|c|c|}
\hline images & \multicolumn{3}{|c|}{ representativeness } & \multicolumn{3}{|c|}{ specialization } & \multicolumn{2}{|c|}{ resemblance } \\
\hline category & high & medium & low & high & medium & low & abstract & realistic \\
\hline disease & $381(51 \%)$ & 295 (39\%) & $78(10 \%)$ & $270(36 \%)$ & $304(40 \%)$ & $181(24 \%)$ & 94 (15\%) & $542(85 \%)$ \\
\hline sign/sympton- & $126(40 \%)$ & 142 (45\%) & 47 (15\%) & 59 (19\%) & $120(38 \%)$ & $136(43 \%)$ & $50(20 \%)$ & 198 (80\%) \\
\hline body part & 39 (71\%) & $16(29 \%)$ & & 25 (45\%) & $17(31 \%)$ & $13(24 \%)$ & $16(42 \%)$ & 22 (58\%) \\
\hline fluid & $5(63 \%)$ & $3(38 \%)$ & & $1(13 \%)$ & $6(75 \%)$ & $1(13 \%)$ & $1(13 \%)$ & $7(88 \%)$ \\
\hline total & 55 & $4 !$ & & & 4 & 331 & 16 & 769 \\
\hline & & & & & & 1133 & & 930 \\
\hline
\end{tabular}

Figure 7: Summary of images in VariMed, according to the different classification criteria

Figure 7 is a chart showing this classification of images in VariMed, semantically classified in concordance with the rest of conceptual information, according to the conceptual fields of disease, sign/symptom, body parts and fluids. Data about their representativeness, specialization and resemblance are also given.

As Figure 7 shows, most of the images are highly representative of the concepts they depict, except for the sign/symptoms category. This is explained in part by the fact that symptoms are naturally a subjective category and therefore it is difficult for them to contain representativeness cues. In the case of specialization, the medium and low specialization tags make up for more than two-thirds of the images, a feature that is consistent with the aim of the database, that is, to target general audiences. Ultimately, realistic images prevail over abstract ones, and only in the psychiatric domain are abstract images more numerous, given the difficulty of depicting metal conditions in terms of realism.

\subsubsection{Metaphorical images in VariMed}

Of a total of 1132 images in the VariMed database, we have identified 84 metaphorical images. Such images are often an eye-catching device in a text, attracting as they do the attention of general readers and experts alike. Observation of the image-text relationship has led us to propose a list of four complementary functions according to their role in terminological work aimed at knowledge dissemination: 
(1) Visually enhancing a conceptual feature of a concept

A)

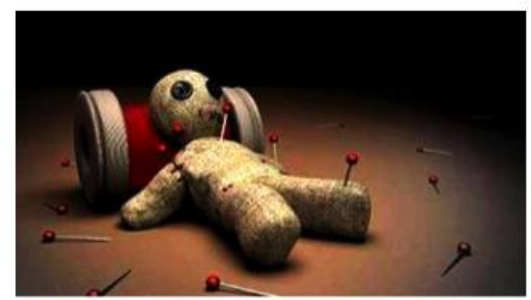

B)

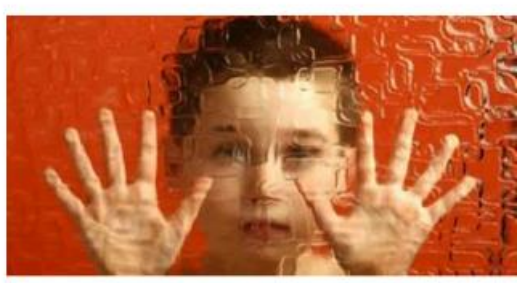

Figure 8: Metaphorical images in VariMed. Source: http://varimed.ugr.es

In (A) the image is used in the entry for somatic symptom disorder, a disorder characterized by a significant focus on physical symptoms - such as pain or fatigue - to the point that it causes major emotional distress and functional problems. The metaphor enhances the feature of "pain", which is a basic feature of the concept. The concept autism is illustrated by the image in (B) in the database. The image metaphorically shows one of the main symptoms of autism, that is, the tendency to isolate oneself. Both images illustrate invisible features of the concepts.

(2) Visually illustrating the concept, following a designation contained in a metaphorical variant.

A)

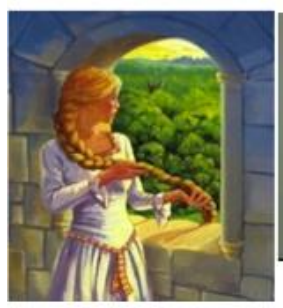

B)

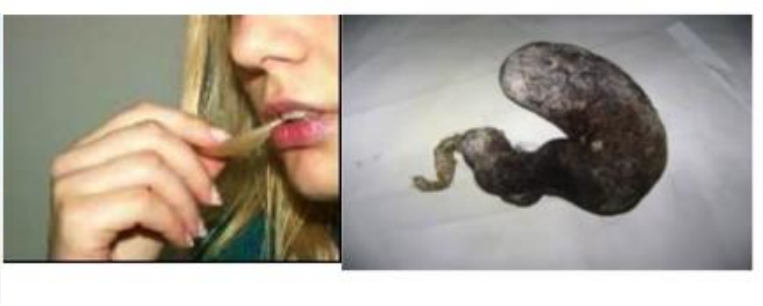

Figure 9: Images illustrating the concept trichophagia from different perspectives. Source: http://varimed.ugr.es/index.php?op=viewconcepto\&idconcepto $=513$

In the case of (A), the metaphorical image is used to represent the metaphorical variant "Rapunzel syndrome", a lexicalization of the concept trichophagia. Neither the variant nor the image can be considered a reflection of a concept feature in this case, in contrast to non-metaphorical images, assigned to the same concept in VariMed. (B) is a nonmetaphorical image that illustrates a basic feature of the concept, contained in the definition of trichophagia: "compulsive ingestion of hair." The image in (C) also shows a conceptual feature, but this focuses on the outcome of the condition: the accumulation of hair in the stomach. 
(3) Enhancing an underlying image schema

In medicine, the colour red is used commonly to point to the location of disease, pain or inflammation is; this underlies the image schema illness is red.

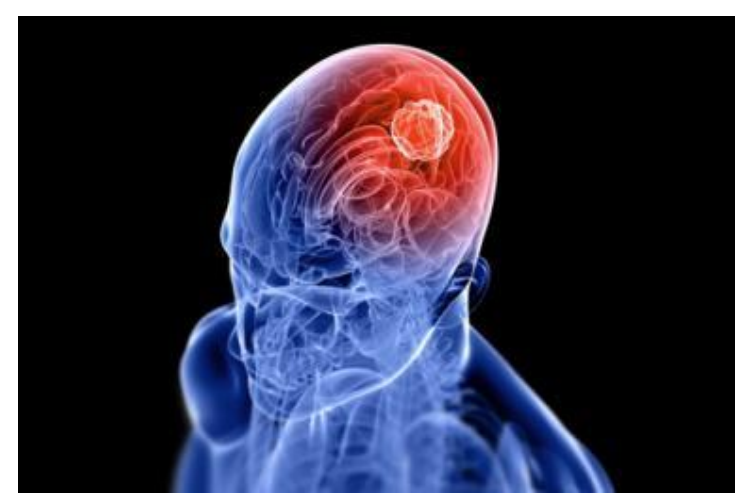

Figure 10: Image revealing the image-schema illness is red. Source: http://varimed.ugr.es /index.php?op=viewconcepto\&idconcepto $=811$

Other common image schema is mental illness is fear, as illustrated in the following image (Figure 11), used for the concept generalized anxiety disorder.

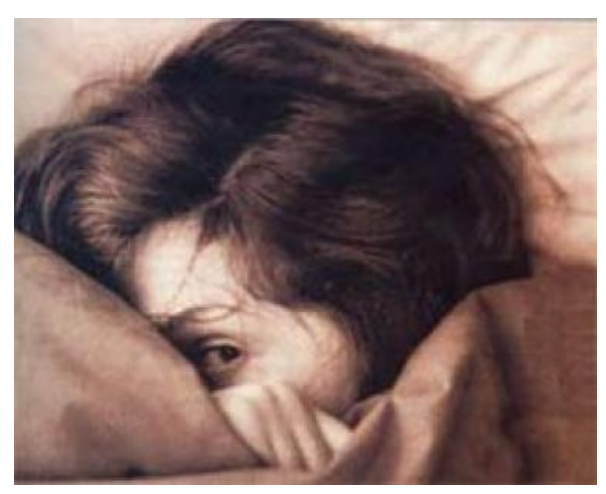

Figure 11: Image revealing the image schema mental illness is fear, as used in the illustration of the concept generalized anxiety disorder. Source: http://varimed.ugr.es/index.php?op= viewtermino\&idtermino $=1028$

\section{(4) Pointing to an existing metonymy}

Metonymic images are commonplace in terminological description: in terminology, metonymy highlights a conceptual relationship between an entity and one of its parts within the same domain (Tercedor Sánchez et al., 2012, p. 33). In fact, metonymy in terminological images is usually considered a prototypical category, which has a spatial part-whole contiguity (i.e., proximity) at its core (Peirsman \& Geeraerts, 2006). The use of such a prototype in the image attempts to make the concept understood. In the following image (Figure 12), the face broken into fragments reveals a prototypical feature of the concept. 


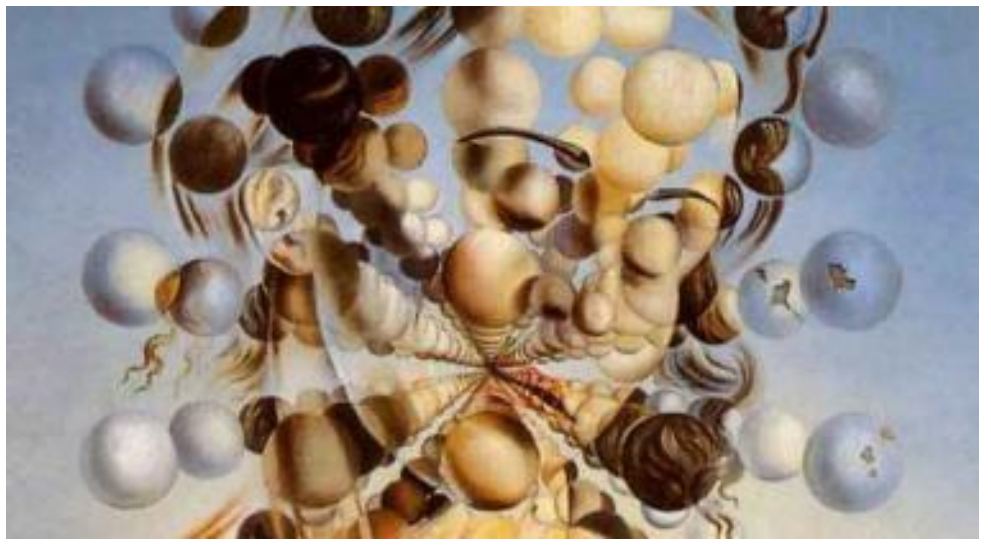

Figure 12: Metonymic illustration of depersonalization disorder. Source: http://varimed.ugr.es /index.php?op=viewconcepto\&idconcepto $=873$

Many eponymic terms and their illustrations in the VariMed database are also metonymic: "Pickwickian syndrome", "Alice in Wonderland syndrome", "Pollyanna syndrome", "Wendy syndrome". They disclose fictional characters' names, a common terminological strategy in psychology, recalling the prototypical behaviour of the particular character. They are therefore metonymies whose understanding is constrained by subjects' background knowledge of the behaviour and peculiarities of the fictional characters.

\subsection{Morphological perspective: the case of runes in medical images}

From a morphological standpoint, medical concepts are conventionally illustrated by images of all sorts, ranging from realistic photographs to drawings, schematic depictions of processes and comic-like representations. There is now an initiative to disseminate materials based on comic-like illustrations that represent the interaction between comics and healthcare or "graphic medicine" (e.g., Green \& Myers, 2010), through several online resources and international conferences on graphic medicine. ${ }^{2}$

In retrieving medical images to illustrate concepts in VariMed, we have come up with an array of morphological features. Using these, we will pay special attention to comic-like representations. 


\begin{tabular}{|c|c|c|}
\hline concepto & categoria & imagen \\
\hline AFASIA ÓPTICA & enfermedad & \\
\hline AFONIAA & signo/sintoma & \\
\hline AFTA & signo/síntoma & \\
\hline AGEUSIA & signo/síntoma & \\
\hline AGNOSIA & enfermedad & \\
\hline AGORAFOBIA & enfermedad & \\
\hline AGRIETAMIENTO & signo/síntoma & \\
\hline ALBINISMO & enfermedad & \\
\hline ALBINISMO OCULAR & enfermedad & \\
\hline ALCAPTONURIA & enfermedad & 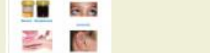 \\
\hline ALCOHOLISMO & enfermedad & \\
\hline ALERGIA & enfermedad & \\
\hline ALERGIA & enfermedad & \\
\hline
\end{tabular}

Figure 13: Random selection of images from VariMed database. The images are varied in terms of morphological features and focus on different aspects of the concepts they depict. Source: http://varimed.ugr.es

Despite comic-like images being potentially less commonplace for illustrating medical conditions, signs and symptoms, they are worth considering, particularly because of the metaphorical relevance of the concept of runes (Kennedy, 1982), also referred to as indexical lines (Cohn 2013, p. 37). Pictorial runes can be defined as non-mimetic graphic elements that contribute narratively salient information (Forceville, 2011, p. 875). Since they are not bound to language, they represent a clear example of image-based metaphorical expression. Runes acquire their meaning in context and, as Forceville (2011) states, are usually quite abstract. 

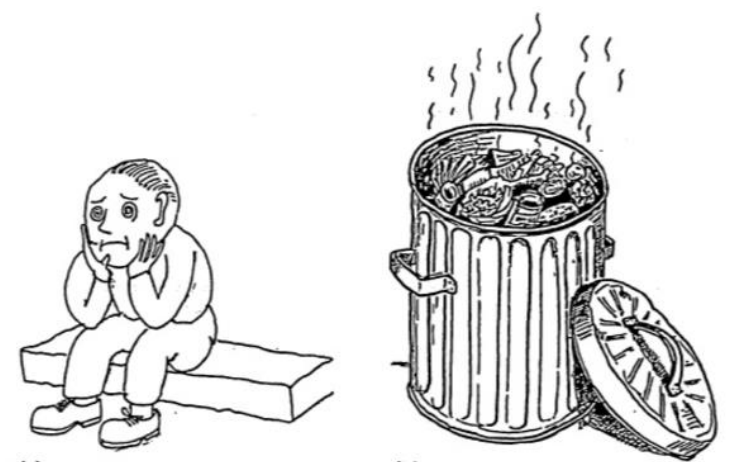

(b)

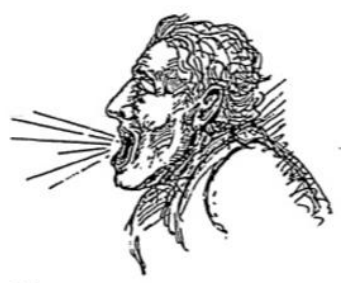

(c)

Figure 6. Pictorial runes: radiating lines for noise.

Figure 14: Pictorial runes. Source: Kennedy (1982, p. 600)

In the context of medicine, runes are typically used in illustrations that have a pedagogical function, such as in the example in Figure 15.

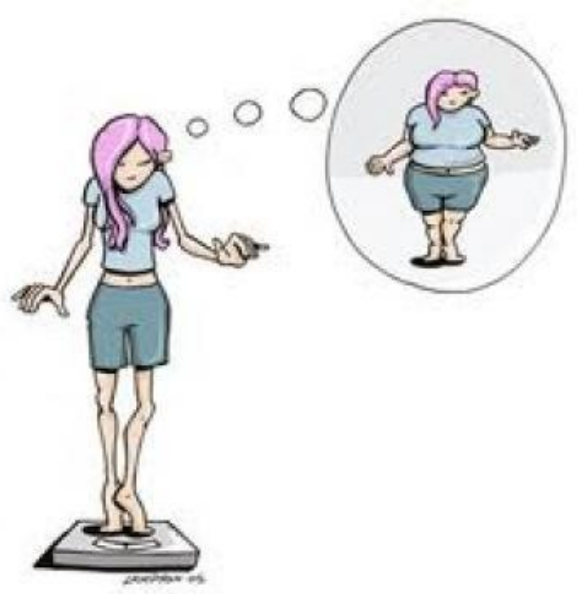

Figure 15: Illustration of the concept trastorno de comportamiento alimentario (eating disorder). Source: http://anorexiabulimiatca.blogspot.com.es/

In the drawing above, circles are used to illustrate imaginative processes. Shaky lines are often used with the intention of illustrating restlessness and stress, as in the case of "acatisia" and "stress" below. 


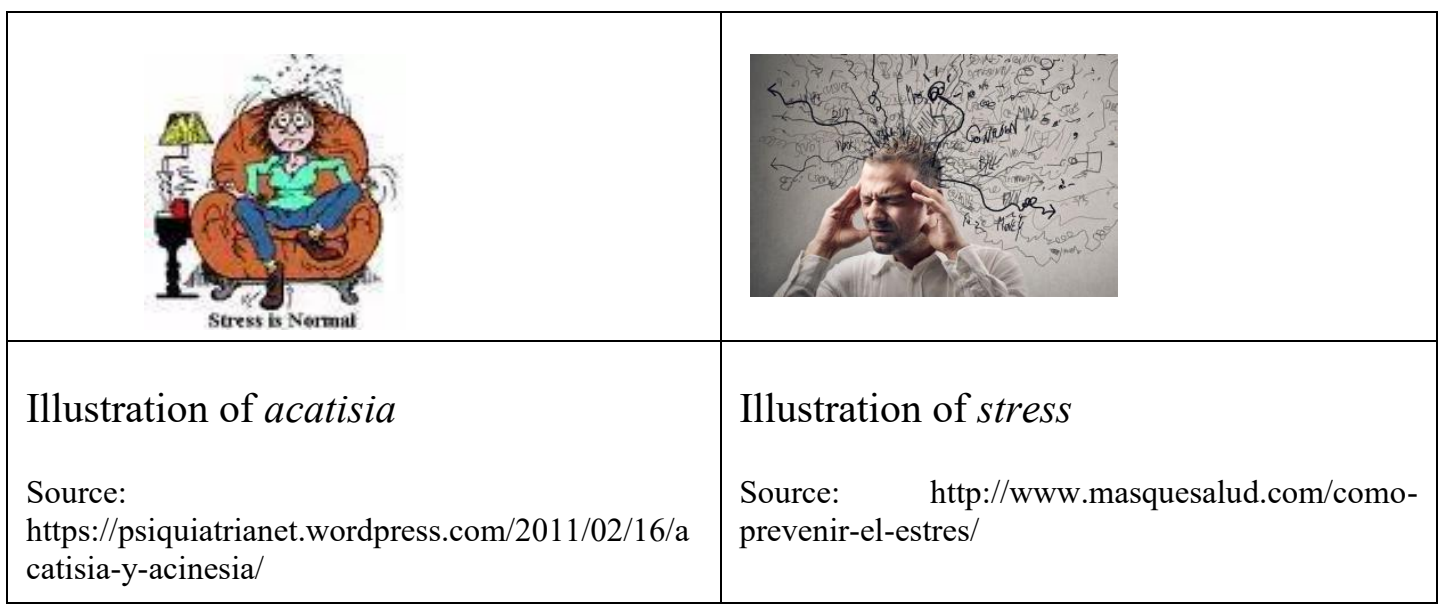

Figure 16: Illustrations of acatisia and stress

Runes can be combined to illustrate complex concepts. The image below illustrates fainting. Two different types of rune are used: the spiral in the eyes depicts instability and the spiral over the head conveys movement.

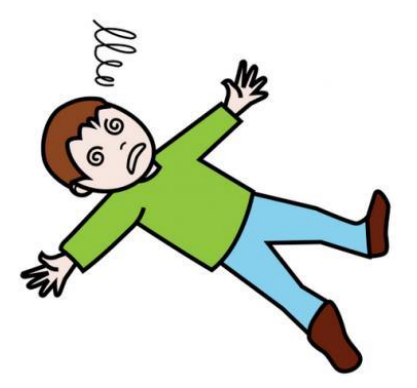

Figure 17: Illustration of fainting. Source: http://varimed.ugr.es/index.php?op=viewconcepto \&idconcepto $=226$

\section{Understanding metaphorical medical images: an experiment}

For a terminological tool to be useful in tasks related to translation and knowledge dissemination, it must contain categories and contents (definitions, contexts, images, conceptual maps) that are understood by and suited to the target users. VariMed contains a number of metaphorical images that illustrate concepts. An analysis of understanding images is needed in order to address their suitability to the tasks of interlinguistic and intersemiotic communication. In this context, we set out to study (a) whether metaphorical images are preferred over non-metaphorical ones for a specific set of medical concepts, and (b) whether metaphorical images are univocal in clearly depicting a specific concept. To find answers, we designed a two-part experiment that corresponds to (a) and (b) above. 


\subsection{Materials and methods}

The experiment consisted of two distinct parts that were carried out in the same session. In part A, to see whether metaphorical images are preferred over non-metaphorical images when illustrating medical concepts, a set of 12 pairs of metaphorical and nonmetaphorical images was chosen from the VariMed project, where each of the 1132 concepts is illustrated by one or more images. The subjects $(n=36)$ were selected on the basis of not having any background of specific medical training, although they had university training, so they were assumed to have basic health literacy. They all had Spanish as L1. They were asked to choose the image that best illustrated different concepts. Definitions of the concepts were provided to the subjects prior to the experiment.
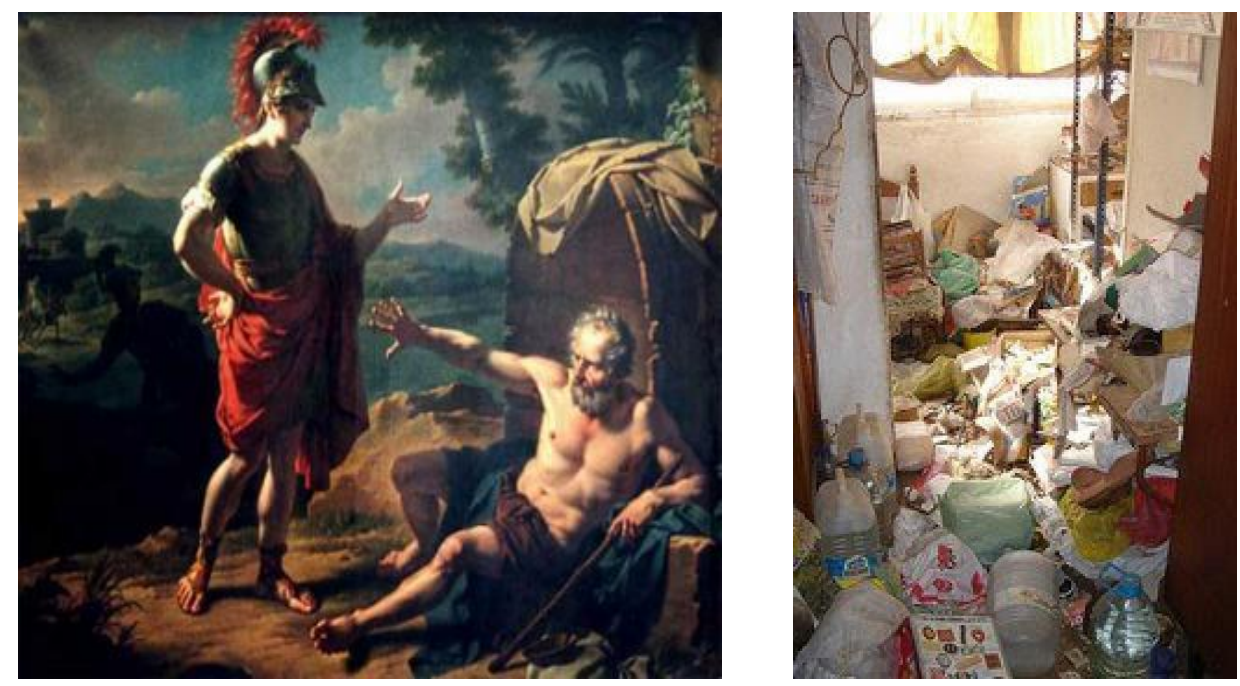

Figure 18: Example of two images used in the experiment. (These were used as stimuli for the concept Diogenes syndrome or senile squalor syndrome, a disorder characterized by extreme self-neglect, domestic squalor, social withdrawal, apathy and compulsive hoarding.)

In part $\mathrm{B}$, in order to analyse the degree to which metaphorical images are easily identified as descriptive of a particular concept, the subjects were asked to match a metaphorical image to the concept that best suited it, out of four choices, one of them being a distractor.

A) Accidente isquémico
transitorio[transient ischaemic
attack]
B) Dolor de cabeza[headache]
C) Ictus[stroke]
D) Cefalea en racimo
transitoria [transient cluster
headache]

Figure 19: Example of metaphorical image and multiple-choice options 
For both parts of the experiment, the subjects were given an on-screen presentation with a time lapse of 20 seconds between stimuli. To pursue spontaneity and ecological validity, the subjects were asked to respond concurrently, that is, simultaneously with the task performance (Göpferich \& Jääskeläinen, 2009, p. 171). They were asked to follow their first intuition and not to go back to change their choice.

\subsection{Results}

In the first part, the subjects where shown two images (one metaphorical, one nonmetaphorical) to illustrate each one of 12 concepts and were asked to choose the image that best represented the concept. The results are shown in Figure 20.

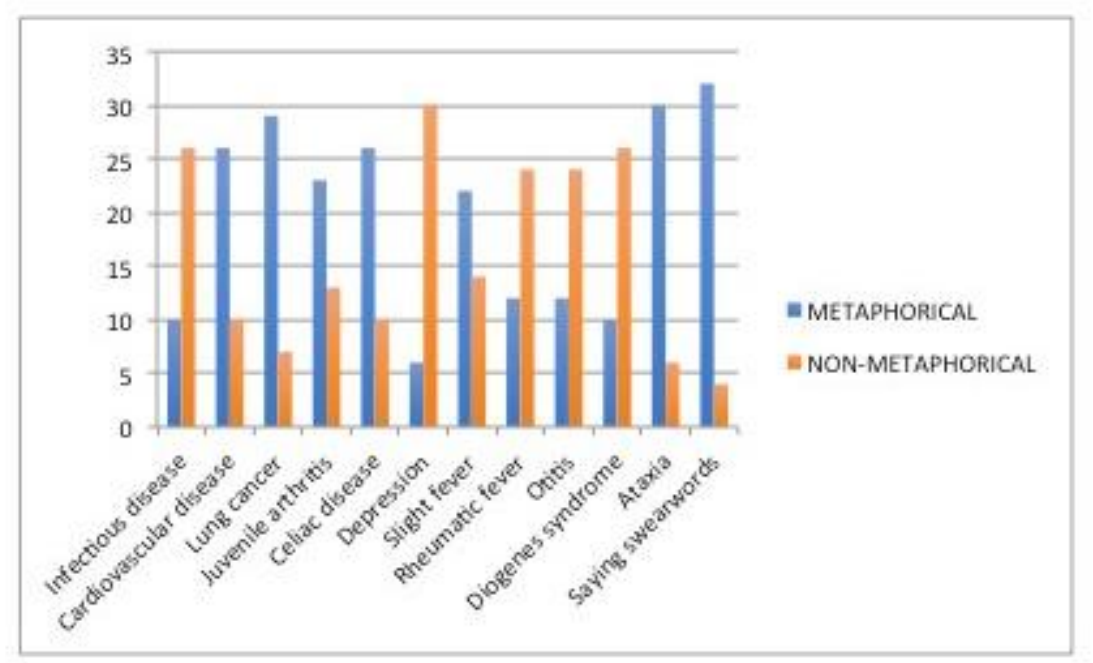

Figure 20: Subjects' preferences for images illustrating 12 concepts

If we look at the overall numbers, after carrying out a statistical analysis, the Mann Whitney U test showed no statistically significant differences between metaphorical $(55.1 \%)$ and non-metaphorical $(44.9 \%)$ choices $(p=0.3683)$.

However, after a more fine-grained analysis, focusing on the concepts for which more than $70 \%$ of the subiects choose metaphorical images, there are some interesting insights to reflect on. For instance, first, there is a preference for the conceptual metaphor red is illness contained in the image to illustrate cardiovascular disease. Secondly, images containing technical data such as changes at the cell level are highly specialized, which might explain the tendency to choose the metaphorical images in the case of the concepts lung cancer and celiac disease, since they are images used in information aimed at the general public. Finally, images containing runes are easily understood and preferred over those at the same level of specialization but which are non-metaphorical (as in the images for ataxia and saving swearwords). In Figure 21 a graph of the metaphorical choices made for each concept is shown. 


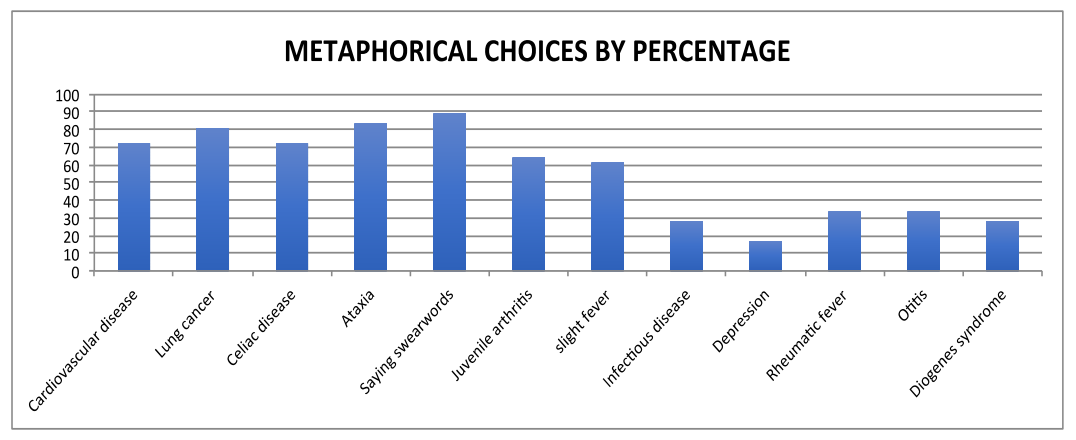

Figure 21: Metaphorical choices for the concepts used as stimuli

In the second part of the experiment, a set of ten metaphorical images was shown to the subjects. They were asked to choose between four possible concepts that could match the image; one of the four concepts was a distractor, a plausible and close-enough concept. The results obtained are shown in Figure 22.

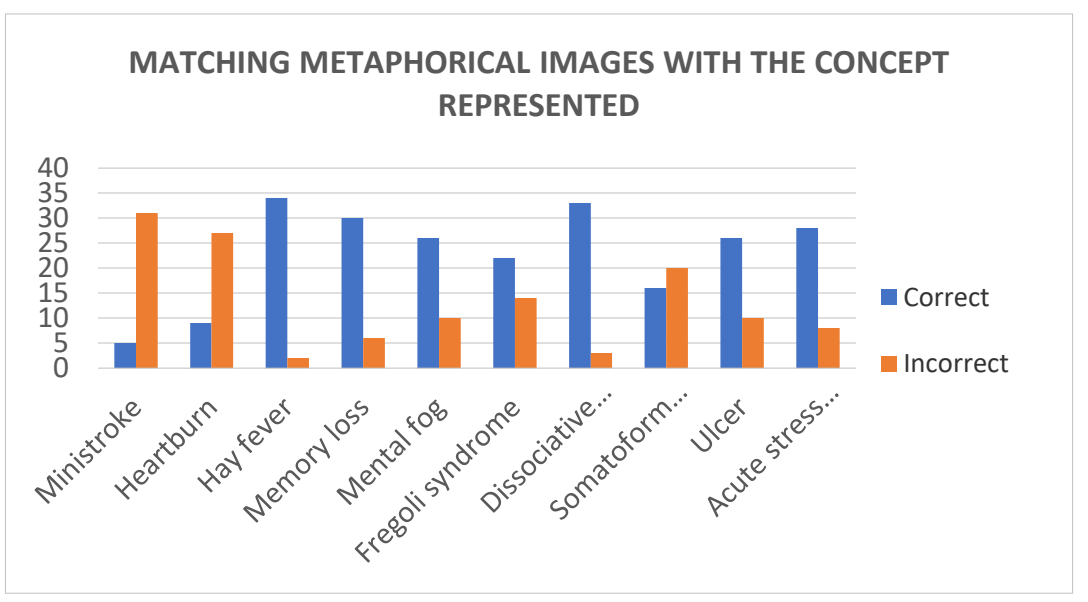

Figure 22: Matching metaphorical images and their depicted concept

The correct match was made in most cases, except for ministroke, heartburn and somatoform disorder. The case of ministroke is interesting: it is a concept illustrated by a blend (see Figure 19), where the concept time is intertwined with the concept pain, and this could be the reason for its not having been identified through the metaphorical image.

Thus, following the experiment, there seems to be a preference for metaphorical over non-metaphorical images used to depict medical concepts. Furthermore, there is a clear identification of red colour as a useful representation of disease, and lines such as those used in comic-like representations are easily understood. These findings suggest that there might be degrees in metaphorical transparency in line with aspects such as register in text, and this phenomenon is an avenue for further research. 


\section{Conclusion}

In today's information society, access to knowledge is necessarily multimodal in nature. This article set out to refine image metaphors in medicine with the aim of studving their role in illustrating information on diseases, signs and symptoms in terminological databases intended for knowledge-dissemination agents such as translators. We have given an overview of the methodological underpinnings regarding image selection and analysis in medical knowledge dissemination and the different roles of metaphorical images as well as their various features and conceptualizations. The results of an experiment that gauges understanding of metaphorical images indicate a preference for metaphorical over non-metaphorical images for illustrating medical concepts; this points to their usefulness as knowledge-dissemination materials. This experimental task of identifying and understanding metaphorical images is pivotal to an understanding of users' preferences and can be applied when dealing with the most suitable multimodal materials and explanations in specialized English-Spanish translation. The choice of a suitable image is crucial to accessing knowledge, the more so in healthcare, since, as Semino et al. (2016: 7) point out, the choice of different descriptions of illness can have both positive and negative effects on the general wellbeing of people.

\section{Funding}

This research is part of CombiMed, Lexical combinations in Medicine: Cognition, text and Context (FFI2014-51899R), a project funded by the Spanish Ministry of Economy, Industry, and Competitiveness.

\section{References}

Apresjan, J. D. (1995). Obraz celoveka po dannym jazyka. in Apresjan Ju.D. Izbrannye trudy. v.2. [Integrated description of language and systematic lexicography]. Moscow, Russia: Jazyki russkoj kul'tury.

Baker, M. (2014). The changing landscape of translation and interpreting studies. In S. Bermann \& C. Porter (Eds.), A companion to translation studies (pp. 15-27). Hoboken, NJ: Willey Blackwell.

Barsalou, L. W. (1999). Perceptual symbol systems. Behavioral and Brain Sciences, 22, 577-660.

Barsalou, L. W. (2008a). Grounding symbolic operations in the brain's modal systems. In G. R. Semin \& E. R. Smith (Eds.), Embodied grounding: Social, cognitive, affective, and neuroscientific approaches (pp. 9-42). Cambridge, UK: Cambridge University Press.

Barsalou, L. W. (2008b). Situating concepts. In P. Robbins \& M. Aydede (Eds.), Cambridge handbook of situated cognition (pp. 236-263). New York, NY: Cambridge University Press.

Brünken, R., Plass, J. L., \& Leutner, D. (2003). Direct measurement of cognitive load in multimedia learning. Educational Psychologist, 38(1), 53-61.

Celikkale, B., Eerdem A., \& Eerdem, E. (2015). Predicting memorability of images using attention-driven spatial pooling and image semantics. Image and vision Computing, 42, 35-46.

Cohn, N. (2013). The visual language of comics: Introduction to the structure and cognition of sequential images. London, UK: Bloomsbury.

Croft, W., \& Cruse, A. (2004). Cognitive linguistics. Cambridge, UK: Cambridge University Press.

Faber, P. (2012). A cognitive-linguistics view of terminology and specialized language. Berlin, Germany: Walter De Gruyter.

Fauconnier, G., \& Turner, M. (2002). The way we think: Conceptual blending and the mind's hidden complexities. New York, NY: Basic Books.

Forceville, C. (2006). Non-verbal and multimodal metaphor in a cognitivist framewok: agendas for research. In G. Kristiansen, M. Achard, R. Dirven, \& F. Ruiz de Mendoza Ibáñez (Eds.), Cognitive 
linguistics: Current applications and future perspectives (pp. 379-402). Berlin, Germany: Mouton de Gruyter.

Forceville, C., \& Urios-Aparisi, E. (2009). Multimodal metaphor (Vol. 11). Berlin, Germany: Walter de Gruyter.

Forceville, C. (2011). Pictorial runes in Tintin and the Picaros. Journal of Pragmatics, 43, 875-890.

Forceville, C. (2016). Pictorial and multimodal metaphor. In N. M. Klug \& H. Stöckl (Eds.), Handbuch Sprache im multimodalen Kontext [The Language in Multimodal Contexts Handbook]. Berlin, Germany: Walter de Gruyter.

Forrester, M. 2000. Psychology of the image. London: Routledge.

Frassanito, P., \& Pettorini, B. (2008). Pink and blue: The color of gender. Child's Nervous System, 24(8), 881-882.

García Morales, C. (2012). ¿Qué puede aportar el arte a la educación? El arte como estrategia para una educación inclusiva. ASRI - Arte y Sociedad. Revista de Investigación, 1, 1-12.

Gibbs, R. (1994). The poetics of mind. Cambridge, UK: Cambridge University Press.

Gibbs, R. (2006). Embodiment and cognitive science. New York, NY: Cambridge University Press.

Göpferich, S., \& Jääskeläinen, R. (2009). Process research into the developmentof translation competence: Where are we, and where do we need to go? Across Languages and Cultures, 10, 169-191.

Green, M. J., \& Myers, K. R. (2010). Graphic medicine: Use of comics in medical education and patient care. BMJ: British Medical Journal, 340, 574-577.

Holyoak, K., \& Hummel, J. (2001). Toward an understanding of Analogy within a Biological Symbol System. In D. Gentner, K. Holyoak, \& B. Kokinov (Eds.), The analogical mind: Perspectives from cognitive science (pp. 161-195). Cambridge, MA: The MIT Press.

Hookway, C. (2007). Peirce on icons and cognition. U. Priss, S. Povolina \& R. Hill (Eds.), Conceptual structures: knowledge architectures for smart applications. Berlin: Springer.

Johnson, M. (1987). The body in the mind: The bodily basis of meaning, imagination and reason. Chicago, IL: Chicago University Press.

Johnson, M. (2005). The philosophical significance of image schemas. In B. Hampe \& J. E. Grady (Eds.), From perception to meaning: Image schemas in cognitive linguistics (pp. 15-33). Berlin: Walter De Gruyter.

Kennedy, J. (1982). Metaphor in pictures. Perception, 11, 589-605.

Ketola, A. (2016). Towards a multimodally oriented theory of translation: A cognitive framework for the translation of illustrated technical texts. Translation Studies, 9(1), 67-81.

Kitao, K., \& Kitao, S. K. (1986). A study of color association differences between Americans and Japanese. Human Communications Studies, 13, 59-75.

Kövecses, Z. (2005). Metaphor in culture: Universality and variation. Cambridge, UK: Cambridge University Press.

Lakoff, G., \& Johnson, M. (1980). Metaphors we live by. Chicago, IL: Chicago University Press.

Lakoff, G., \& Turner, M. (1989). More than cool reason: A field guide to poetic metaphor. Chicago, IL: University of Chicago Press. Merwin, W. S. 1973. Asian Figures. New York: Atheneum.

Leppink, J., \& van der Heuvel, A. (2015). The evolution of cognitive load theory and its application to medical education. Perspect Med Educ, 4, 119-127.

López-Rodríguez, C. I., \& Tercedor-Sánchez, M. (2017). Identification and understanding of medical metaphors by non-experts. F. Ervas, E. Gola \& M.G. Rossi (Eds.), Metaphor in Communication, Science and Education (pp.301-342). Berlin: Mouton de Gruyter.

Nikolajeva, M. (2014). Emotion ekphrasis: Representation of emotions in children's picturebooks. In D. Machin (Ed.). Visual communication (pp. 711-728). Berlin: Mouton De Gruyter.

Peirsman, Y., \& Geeraerts D. (2006). Metonymy as a prototypical category. Cognitive Linguistics, 17(3), 269-316.

Pragglejaz Group. (2007). MIP: A method for identifying metaphorically used words in discourse. Metaphor and Symbol, 22(1), 1-39.

Prieto Velasco, J.A., \& Faber, P. (2012). Graphical information. P. Faber (Ed.), A cognitive-linguistics view of terminology and specialized language (pp. 225-248). Berlin: Mouton de Gruyter. 
Radden, G. (1992). The cognitive approach to natural language. M. Pütz (Ed.), Thirty years of linguistic evolution: Studies in honour of René Dirven on the occasion of his sixtieth birthday (pp. 513-541). Amsterdam: John Benjamins.

Rosch, E. (1978). Principles of categorization. In: E. Rosch, \& B. B. Lloyd (Eds.), Cognition and categorization (pp. 28-49). Hillsdale, NJ: Erlbaum.

Sánchez Benítez, G. (2009). El uso de las imágenes en la clase E/LE para el desarrollo de la expresión oral y escrita. Revista Suplementos marco ELE 8(2009), 1-17.

Semino, E., Demjen Z., \& Demnen, J. (2018). An integrated approach to metaphor and framing in cognition, discourse, and practice, with an application to metaphors for cancer. Applied Linguistics 39 (5), 122.

Smith, E. E., \& Kosslyn, S. M. (2007). Cognitive psychology: Mind and brain. Upper Saddle River, NJ: Pearson/Prentice Hall.

Sperber, D., Cara, F., \& Girotto, V. (1995). Relevance theory explains the selection task. Cognition, 57, 31-95.

Tercedor Sánchez, M. (2011). The cognitive dynamics of terminological variation. Terminology, 17(2), 181-197.

Tercedor Sánchez, M. (2017). Bases cognitivas de la variación terminológica en medicina. M. A. Candel Mora \& Ch. Vargas Sierra (Eds.), Temas actuales en terminología y estudios sobre el léxico (pp. 27-48). Granada: Comares.

Tercedor Sánchez, M., \& Jiménez Crespo, M. A. (2008). Accesibilidad, imágenes y traducción técnica. C. Jiménez Hurtado \& Ana Rodríguez Domíngue (Eds.), Accesibilidad a los medios audiovisuales para personas con discapacidad (AMADIS 07) (pp. 120-132). Madrid: Real Patronato sobre discapacidad.

Tercedor Sánchez, M., Alarcón Navío, E., Prieto-Velasco, J.A., \&López-Rodríguez, C. I. (2009). Images as part of technical translation courses: Implications and applications. Jostrans: The Journal of Specialised Translation, 11,143-168.

Tercedor Sánchez, M., López Rodríguez C. I., Márquez Linares C., \& Faber, P. (2012). Metaphor and metonymy in specialized language. P. Faber (Ed.), A cognitive-linguistics view of terminology and specialized language (pp. 33-72).Berlin: Mouton de Gruyter.

Tversky, B. (2001). Spatial schemas in depictions. In M. Gattis (Ed.), Spatial schemas and abstract thought (pp. 79-112). Cambridge, MA: MIT Press/Bradford Books.

Wierzbicka, A. (1972). Semantic primitives. Frankfurt: Athenäum.

Yimou, Z. (2017). The Great Wall. [Film]. China: Legendary Entertainment, Le Vision Pictures, China Film Group Corporation, Atlas Entertainment.

1 Source:http://www.heart.org/HEARTORG/Conditions/More/Cardiomyopathy/Is-Broken-HeartSyndrome-Real_UCM_448547_Article.jsp\#.WDaxs2ThBFQ

2 For example, https://medicinagrafica.com in Spanish and http://www.graphicmedicine.org in English. 